\title{
ADOLESCENCE
}

Competent professional assistance can meet the challenges of keeping parents and patients on a stable and sound emotional course as the diabetic adolescent grows up.

\section{Parental Attitudes and Their Influence on the Medical Management of Diabetic Adolescents}

\author{
BARBARA J. LAHOOD, A.C.S.W.*
}

C ited activity because of chronic illness are more prone to psychologic difficulties than are normal healthy children. ${ }^{1}$ Psychologic difficulties in the juvenile diabetic are often the result of rigid and overprotective enforcement by parents of their child's medical regimen. Diabetes in children is usually more severe than in adults; it typically develops abruptly, and before the discovery of insulin it soon led to death. Currently, however, with adequate medical supervision and treatment, and intelligent cooperation on the part of the patient and the parents, a diabetic child cannot only survive but be guided through intervening illnesses and changing life situations to achieve normal adulthood."

Often the juvenile diabetic remains in good medical control until he either reaches or is in the throes of adolescence. Many explanations have been given for adolescents who repeatedly go into acidosis. Often it has been assumed that these patients, despite careful efforts at regulation, suffer from metabolic eccentricities which make them react severely to slight changes in diet, insulin intake, exercise or general health. Susceptibility to infection also may be held responsible. The im-

From the Department of Social Work, University of Michigan Medical Center, Ann Arbor, Mich. 48104.

* Clinical Social Worker, C. S. Mott Children's Hospital.

Presented in part at the 5th Annual Conference of the American Association for Child Care in Hospitals, University of Michigan Medical Center, Ann Arbor, Mich., May 7-10, 1969. portance of emotional disturbances has been appreciated and the acidosis, at times, has been attributed to effects of emotional factors upon the metabolic processes..$^{3-5}$

While all these explanations may be considered reliable, there are also some adolescents, in good control previously, who induce repeated episodes of acidosis through conscious sabotage of their medical regimen. Parental attitudes toward the diabetic child are obvious factors in his response. I shall discuss how some of these attitudes, unless modified to allow more independence when needed, can provoke an adolescent's undermining of previously adequate diabetic control. To do so, it is necessary to understand the meaning for parents of the child's chronic illness. I shall point out also how health professionals, in collaboration with the pediatrician, can assist parents of diabetic adolescents toward a more meaningful and healthy participation in their child's care.

\section{Emotions of the Parents}

When a previously healthy child becomes seriously ill, the parents' immediate response is anxiety concerning the acute symptoms, to be followed by relief on learning that the child's life is not seriously threatened. The shock tends to persist, however, when they learn that the child has a chronic illness which carries some disability. When this chronic illness is diabetes the physician must strike a balance between instructing the parents and child on the seriousness of the condition and 


\section{PARENTAL ATTITUDE INFLUENCE ON MANAGEMENT OF DIABETICS}

the need for continuous treatment, and the desire not to provoke extreme and unnecessary anxiety. ${ }^{6,7}$

In the new relationship which ensues, the parents face a challenge. The sick child needs extra or special care, and his increased dependency entices the parents to give him greater protection. ${ }^{8}$ At the same time, the parents must not lose sight of the child's growth potentials. Parents' handling of their grief shows, understandably, great individual variations not only in the intensity and the control of their feelings, but also in the time needed to accept the new reality and the limitations which may be imposed upon their child and themselves. ${ }^{2}$

As with other chronic illnesses, families of diabetic children tend to search for explanations and causes for the disease. The theories they arrive at may consist of various mixtures of guilt, hostility and preconceived notions. ${ }^{10,11}$ An example:

Sharon, 11 years old, had been admitted to the hospital 17 times within two years for treatment of acidosis. She was not given her insulin at home as prescribed and did not follow her diet. Her parents vacillated between blaming the mother's fall down the stairs while pregnant, or their daughter's contact with a diabetic uncle, as the cause of the disease. They openly expressed the notion that the chronicity of their daughter's disease was their punishment for past misdeeds. Believing that she would be harmed by regular injections of medicine or insulin, they acted out their ambivalence by administering the correct dose on alternate days.

Many families have difficulty in accepting that they are dealing with an incurable disease. They grope for assurance that diabetes will become curable some day, or that their child may "outgrow" it. ${ }^{12}$ Their hopes may be determined by a wide range of superstitions, medical information and misinformation. In some instances, when recognition of the child's disability poses an unbearable threat to the parent, the denial of the chronicity may assume tremendous proportions and may last for years.

Parents may respond not only with denial, but with feelings of guilt over their child's illness. Day after day, the same questions crop up in many variations. What omission or commission on their part caused or precipitated the child's illness? What part does heredity play? For what old sin are they being punished?

When the sense of guilt is unbearable, parents may attempt to project it by blaming either the child, the marital partner or the family doctor who "failed to recognize its earliest signs." Parental guilt is difficult to resolve and their response to it may appear as desperate anger over the disappointment that fate has meted out to them. ${ }^{18}$ This anger, which may include unconscious death wishes, is in conflict with the genuine love for their child, and may find expression in overprotection and in a resurgence of anxiety for the child's life. ${ }^{14}$

\section{Reactions of the Patient}

Indeed, the adolescent demands much attention. He needs to know what we think of him and what we expect of him in his active quest in forming and checking out his identity. Impelled to work out opinions, plans and hopes of his own, he wants to be himself and yet is uncertain of himself. He may need temporarily to reject or depreciate his family's and his society's ways and ideals, fearing that he will be cast in a mold not his own. Those who in their early years develop feelings of competency, who have parents who are strong but not intrusive, who have had as ideals people who did not evoke disillusionment, are much less likely to find themselves vacillating and uncertain or persistently needing to adopt ideas or activities contrary to their parents' or their society's standards.

In adolescence, when a boy or girl is striking out to become more independent of his parents and to lead a more individual life, an overprotective environment often leads to destructive, defiant rebellion. Helping overprotective parents shift from earlier modes of management to one which allows for the chaotic, often frustrating but natural task of maturation becomes an essential component of good medical care.

Most adolescents, if given the opportunity of experimenting on their own, praise for what is good, and consistent criticism of their excesses, will free themselves satisfac- 


\section{LAHOOD}

torily from their childhood attachments and achieve their own mature ways of thinking and living. Support and guidance without interference with their freedom to work these out give them the confidence they must have if they are indeed to make a free choice. ${ }^{15}, 16$

For an adolescent to behave in a mature fashion one day, as if trying it out, and to be very childish the next, as though spent by the previous day's effort, is typical rather than unusual. Maturity is a goal toward which adolescents are striving, not a state they have achieved.

Too many adults and parents complain of adolescents' immaturity without appreciating that immaturity is normal at this time of life. It is the adults' management of young adolescents in ways which tend to perpetuate immaturity which we should strive to change.

\section{Preventive Counselling by Health Professionals}

In university hospitals and medical centers there is an increasing interest in practicing a comprehensive approach to the understanding and care of the adolescent patient, whether he is labeled as "sick" or "healthy." In such centers, a health professional of the pediatric team (be he social worker, psychologist or clinical nursing specialist) is designated to help provide the families of adolescent diabetics with continuous support and evaluation which could prevent or remedy unhealthy parental attitudes. Continuing support and evaluation obviously means more than the well meaning but superficial questions of "How is the diet?" or "Do you have any problems?"

Families often give the impression of stability and of warm, affectionate relationships when their contacts with the examiner are brief. But more detailed interviews and a sharper focus (by either the physician or his associate) may reveal that the child's illness is eliciting a pathologic interaction. For example, the diabetes may be giving the mother a tool with which she can retain her hold on a child who has begun to stray from her. The mother may insist that she is the only one who can make sure that the diet is properly adhered to.
Mrs. A. repeatedly emptied her 17-year-old daughter's purse in an effort to discover candy or some other forbidden fruit. She frequently embarrassed her daughter by insisting on ordering for her when the family dined out. In sheer frustration, her daughter finally stopped administering her own insulin, acidosis ensued and the young lady's rebellion was accomplished.

Such perfectionistic overcontrol of diet or administration of injections can become expressions of the mother's need for absolute power over the child. Here the basic attitude toward the child is aggressive and subduing, and the perfectionistic quality of the cooperation seems to be an attempt to win a victory over diabetes even though the child's personality may be crushed in the process.

More emotional upsets seem to be produced in diabetic adolescents from overprotectiveness on the part of the parents than from bewilderment or confusion on the part of the child. A diabetic adolescent may cheat seriously on his diet or withhold his insulin as an expression of rebellion against rigid and infantilizing parental authority. Thus diabetes can provide an admirable instrument to enable the affected adolescent to draw attention to himself, to get into the hospital or to create a disturbance. ${ }^{17}$ It frequently takes a series of interviews to enable him to admit his diabetic mismanagement and the reasons for it. That is why the physician and his associate must not only talk with the adolescent alone and in detail about his disease and its management, he must also allot sufficient time for discussions with the family concerning the management of the diabetes as an ongoing process.

\section{Maintaining a Healthy Environment}

How can we intervene when unhealthy parental attitudes may provoke conscious diabetic mismanagement by the adolescent? How can we assist parents to relax from their previous protective approach during childhood to appreciate that delicate balance of the dependent-independent strivings of the maturing diabetic adolescent? While we expect an adolescent to take increasing responsibility for the management of his medical regimen, can we expect all parents who previously have been primarily responsible for care and who 


\section{PARENTAL ATTITUDE INFLUENCE ON MANAGEMENT OF DIABETICS}

have experienced continuous apprehension due to the illness to shift as easily as we may anticipate into a more lenient participation in their adolescent's care? Should we not continually evaluate the parents' managernent of their child's medical problem to determine what psychologic effect this management has on family situations?

If at the time of the first diagnosis, the child is hospitalized in a medical center where collaborative services are used, I suggest that the pediatrician call upon the appropriate team member to become familiar with the patient and family. The team member's initial effort would be to supplement medical information by cvaluating in general family relationships and attitudes and assessing the ability of the family to carry out medical instructions. When such consultation indicates the need for continued contact, further evaluations could then be aimed at ascertaining as many details as possible about the way in which management tasks are being handled. This ongoing evaluation process is not to encourage the diabetic child to be the focus of all family concern and conversations, but rather to pave the way for more favorable conditions and communications within the family when both parents and child face the task of adolescence.

How can the pediatrician in private practice also obtain this sort of consultative assistance with his diabetic patients who do not require hospitalization? One approach would be to refer the patient and family to a community agency; and this is sometimes done.

Another means is developing. Several pediatricians may use the consultative services of a full-or part-time social worker employed to work with patients and families who are experiencing social and emotional troubles related to medical problems in the child. The social worker, in collaboration with the pediatricians, not only follows families and patients on a consistent basis, but also when the patient requires such, can serve as a liaison between the pediatrician's office and such com munity systems as the school, public health department, etc.

Whatever means the pediatrician chooses, success in treatment of diabetes in adolescence must depend upon a long-range well-planned program which includes careful evaluation and treatment of social, psychologic and behavioral problems; on thorough instruction of the parents in their changing responsibilities in the medical management of their child; on prevention and correction of unhealthy parental attitudes; and, finally, on continual encouragement of the adolescent to live a happy and useful life despite his illness.

\section{References}

1. Fischer, A. E.: Factors responsible for emotional disturbances in diabetic children. The Nervous Child 7: 78, 1948.

2. Bruch, H. and Hewlett, I.: Psychologic aspects of the medical management of diabetes in children. Psychosom. Med. 9: 205, 1947.

3. Rosen, H. and Lidx, T.: Emotional factors in the precipitation of xecurrent diabetic acidosis. Ibid. 11: $211,1949$.

4. Bailey, C. C.: Diabetes in adolescence. Med. CIin. N. Amer. 29: 45 l, 1965.

5. Daniels, G. E.: The role of emotion in the onset and course of diabetes. Psychosom. Med. 10: 288,1948 ,

6. Bruch, H.: Physiologic and psychologic interrelationships in diabetes in children. Ibid, 11: 200 , 1949.

7. Tolstoi, E.: The objectives of modern diabetic care. Ibid. 10: 291, 1948.

8. Bozcman, M. F., Orbach, C. E. and Sutherland, A. M.: The adaption of mothers to the threatened loss of their children through leukemia. Cancer 8: 1, 1955

9. Tisza, V. B.: Management of the parents of the chonically ill child. Amer. J. Orthopsvchiat. 32: $53,1962$.

10. Bruch, $H_{.}$: Physiologic and psychologic interrelationships in diabetes in children. Psychosom. Med. 11: 201, 1949.

11. Falstein, E. I. and Judas, I.: Juvenile diabetes and its psychiatric implications. Ibid. 16: 330, 1954.

12. Bruch, H.: Physiologic and psychologic interrela. tionships in diabetes in children. Ibid. 11: 202, 1949.

13. Benedek, T.: An approach to the study of the diabetic. Ibid. 10: 285, 1948.

14. Lewis, M.: The management of parents of acutely ill children in the hospital. Amer. J. Orthopsychiat. 32: 61,1962 .

15. Freud, A.: Adolescence. The Psychoanal. Stud. Child 13: 255, 1958.

16. Gallagher, J. R. and Harris, H. I.: Emotional Problems of Adolescents. New York, Oxford University Press, 1958.

17. Pyke, D.: Diabetes mellitus. In Psychosomatic Disorders in Adolescents and Young Adults, Ham. bling, J. and Hopkins, J., eds. New York, Pergamon Press, 1965, p. 105. 